\title{
Pregnancy Rate and Foetal Mortality in Aleutian Disease Virus Infected Mink
}

It is well known observation that farms contaminated with Aleutian Disease (AD) virus on an average have a lower breeding result than not infected farms. In the Danish eradication programme a farm may be registered as an A-farm, if a number of conditions are fullfilled. Among the conditions are yearly testings by countercurrent immunoelectrophoresis of all breeders or certain groups of these. The testing is carried out by the laboratory of the Danish Fur Breeder's Association. Starting with the testing of 30.000 samples in 1976 the number of tests were 2.9 millions in 1986. The number of A-farms was more than 1,500 out of 4236 in 1986. The A-farms had in 1986608,116 breeders with an average breeding result of 4.81 compared to the not tested farms that have an average of 4.37 kits per mated female. While the number of breeders has increased from 1.0 million in 1980 to $2.1 \mathrm{mil}-$ lion in 1986, the percentage of infertile females has in the same period decreased from 14.7 to 10.9 with an average breeding result increasing from 4.09 to 4.69 (Anon. 1986).

In spite of the careful registration of the litters, the actual number of kits born cannot be stated, as countings are not carried out at the same age of the newborn in the various farms, and the kits dying within the first 24 $h$ are usually not registered. The negative influence of $\mathrm{AD}$ on the average litter size is, however, essentially found to be due to the increased number of females not giving birth but also because of early deaths of kits. In addition AD-positive females may neglect their offspring and have poorer lactation.
In 1983 a small experiment was performed, where females were inoculated with virulent AD-virus strain just after the mating period. In a small control group of 6 females, which were AD-negative before mating, no kits were born. By post mortems carried out just after expected delivery 5 of the 6 females showed obvious signs of having contained embryos. In order to test the hypothesis that AD-negative females infected with AD-virus just before or during pregnancy have a higher risk of abortations than chronically infected females, but also that such primary infected females should not necessarily be registered as permanently infertile, the following experiment was carried out:

A total of 51 standard females were purchased. Out of these 21 were from a heavily infected farm and they were seropositive for AD. A group of 30 AD-negative females were from an A-farm and found sero-negative. They were all mated during the period March 8 to March 24. Most of them were mated twice by fertile males. On March 25 all females were injected with $0.1 \mathrm{ml}$ of virulent AD-virus subcutaneously. The females gave birth during the period April 28 to May 15. The results obtained are shown in Table 1.

The pregnancy rate was perhaps somewhat lower than might be expected. The change of feed might have influenced these results. The low average number of kits per female of 2.3 has been observed in AD-positive farms during 1986 especially when AD has been spread in a large farm during the previous winter. In other farms which pur- 
Table 1. The distribution of fertility, pregnancy and litter size an AD-positive and $\mathrm{AD}$-negative mink inoculated with $\mathrm{AD}$-virus just after mating.

\begin{tabular}{lrr}
\hline & \multicolumn{2}{c}{ AD-status before mating } \\
\cline { 2 - 3 } & AD-positive & AD-negative \\
\hline Number of females & 21 & 30 \\
Number of females giving birth & $8(38 \%)$ & $12(40 \%)$ \\
Total number of kits & 53 & 37 \\
Litter size & 6.88 & 3.08 \\
Average no. of kits per female & 2.30 & 1.12 \\
$\begin{array}{l}\text { No. of pregnant females not giving } \\
\text { birth observed post mortem }\end{array}$ & $3(14 \%)$ & $14(47 \%)$ \\
$\begin{array}{l}\text { No. of non-pregnant females } \\
\text { observed post mortem }\end{array}$ & $10(48 \%)$ & $4(13 \%)$ \\
Total no. of pregnant females & $8+3(52 \%)$ & $12+14(87 \%)$ \\
\hline
\end{tabular}

chased from such a farm with increasing spread of $A D$, the number of kits has been very low, 1.5-2.8. The level of pregnancies in the AD-positive animals is at a level that has often been seen in AD-positive farms. It is indicated from the table that there may be a high rate of infertility among the ADpositive females, as 10 out of 21 females did not become pregnant, but the number of aborting females was relatively low (3 out of 21). If the AD-positive females give birth at all, they have a large or at least a normal litter (6.88). If the females are newly infected, a pregnancy rate of $87 \%$ does not improve the breeding result because only 12 out of 26 pregnant females gave birth and the litter size was small (3.08). In this groups the number of abortions was high, 14 out of 30 . Consequently the average no. of kits per female became extremely low (1.12 kits per female).

The reported experiment was carried out because of the suspicion that infertility need not be a result of a chronic AD-infection and also that acute primary infection during pregnancy is extremely dangerous. The material is limited in size with a total of 51 females, but the results are quite clear:
1. A chronic infection with $A D$ does not prevent the female from giving birth to a normal litter. It is, however, difficult to estimate the infertility rate due to chronic AD and it would probably only be in very special cases that a farmer would want to maintain an infertile female for breeding.

2. The mink embryos of a previous AD negative female are extremely vulnerable to the AD-infection. This is a very important conclusion from the farmer's point of view. In addition it adds to the general understanding of the AD-infection. It shows that in this respect $\mathrm{AD}$ behaves like essentially all primary virus infections during pregnancy.

\section{Mogens Hansen,}

The Danish Mink Breeder's Association.

\section{Ebba Lund,}

The Royal Veterinary and Agricultural University, Department of Veterinary Virology and Immunology, Denmark.

\section{References}

Anon: Avlsresultater 1981-1986, Dansk pelsdyravlerforening nr. 10, 1986, 696-698.

Hansen $M$ : Neonatal Aleutian Disease in Mink. In press.

(Received August 11, 1988).

Reprints may be requested from: Mogens Hansen, Danish Fur Breeders' Assocoation, 60 Langagervej, DK-2600 Glostrup, Denmark. 